\title{
Estructura de una broma
}

\author{
Structure of a joke \\ DOI: https://doi.org/10.5377/koot.v0i11.10735 \\ URI: http://hdl.handle.net/11298/1191
}

Rubén Fúnez

Doctor en Filosofia y catedrático de filosofía y ética Universidad Tecnológica de El Salvador ruben.funez@utec.edu.sv

Palabras clave: La broma - crítica e interpretación. Trucos - anécdotas, chistes, sátiras. Humorismo - anécdotas, chistes, sátiras. Sátira - anécdotas, chistes, sátiras. Parodia.

Key words: The joke - criticism and interpretation. Tricks - anecdotes, jokes, satires. Humor - anecdotes, jokes, satires. Satire - anecdotes, jokes, satires. Parody.

\section{Introducción}

Milan Kundera nació en Brno, Checoslovaquia, el 1 de abril de 1929, fue profesor en la Escuela de Estudios Cinematográficos de Praga, puesto que perdió tras la invasión rusa de 1968. Sus obras fueron entonces retiradas de la biblioteca de su país y su nombre desapareció de los manuales de historia literaria. Desde 1975 reside en París. La primera novela de Kundera, La broma, obtuvo el premio de la Unión de Escritores Checoslovacos en 1968. La edición que comentamos es la segunda reimpresión del 2006, realizada por la Editorial Seix Barral.

El propósito de este ensayo es presentar ante el lector la estructura de cualquier broma. Para ello, lo hemos dividido en cinco partes. En la primera, describimos la broma. En la segunda, analizamos al sujeto que padece la broma. En la tercera, presentamos lo que llamamos los hermeneutas de la broma, indicando con ello que siempre, junto a una broma, hay sujetos muy inteligentes que la interpretan. En la cuarta, que es indudablemente la parte central de nuestro ensayo, describimos las consecuencias que se desprenden de una broma, y aquí lo que tenemos que tener presente es la capacidad que tiene una broma para determinar la totalidad de la vida del bromista. En la quinta, describimos lo que llamamos la redención del bromista. 
Al estructurar de este modo nuestro ensayo, buscamos llamar la atención del lector sobre nuestra clave de lectura de esta novela: no se pretende hacer una lectura sistemática de la novela. En rigor, la novela ha sido un medio para hacer la fenomenología de una broma, no sólo de la broma a la que se refiere nuestro novelista, sino de cualquier broma.

\section{La broma}

La primera cuestión que tenemos que analizar es precisamente en qué consiste la broma. Una de las cosas en las que tenemos que reparar es que no todas las bromas tienen el mismo propósito. Es probable que bromear tenga como propósito crear un momento festivo, en el que se involucren activamente, tanto el bromista como el que padece la broma. La consecuencia de este tipo de broma, generalmente, es un ambiente de camaradería. Pero hay que señalar que la broma busca la creación de este ambiente. En este sentido, podemos describir a este tipo de bromas como el tipo de una broma inocente.

En cambio, hay un tipo de bromas que pretende, principalmente, hacer sentir incómodo a aquel con quien se bromea. La broma que en este momento estamos comentando dice explícitamente que tiene como propósito herir, asombrar y confundir; por eso más que broma deberíamos denominarla ironía, sarcasmo, o burla. Kundera la describe en los siguientes términos:

Lo cierto es que, en realidad, yo estaba de acuerdo con todo lo que decía Marqueta, hasta creía en una inminente Revolución en Europa occidental; sólo había una cosa con la que no estaba de acuerdo: que estuviera contenta y feliz cuando yo la extrañaba. De modo que compré una postal y (para herirla, asombrarla y confundirla) escribí: ¡El optimismo es el opio del pueblo! El espíritu sano huele a idiotez. ¡Viva Trotsky! (Kundera, 1967, p. 41).

Es evidente que se intenta incomodar. De hecho, en esta broma se recurre justamente a expresiones que probablemente quienes las usan son justamente los adversarios, y los adversarios no buscan estimular, sino que lo que hacen es descalificar. Quizás entonces lo que tenga de broma es que el bromista tampoco cree lo que sus adversarios le critican y piensa, erróneamente, que el destinatario de la broma sabe perfectamente que ambos viven por los mismos ideales y que, por lo tanto, no tomará en serio el contenido. Es decir, el bromista, en este caso, busca los efectos de la broma sin que se tenga en cuenta la materialidad de esta; busca herir, incomodar, pretendiendo hacerlo con recursos en los que ni él cree. Es precisamente en esto en lo que consiste la broma.

Por esta razón no parece convincente la explicación que se da de la reacción desencadenada por dicha broma cuando apunta que "la alegría de aquella época 
no era amante de la picardía y la ironía, era una alegría [...] seria, que se daba a sí misma el orgulloso título de 'optimismo histórico de la clase triunfante', una alegría ascética y solemne" (Kundera, 1967, p. 37). ${ }^{1}$

No queremos negar que en la realidad existen personas tan solemnes que son incapaces de resistir la más mínima broma, incluso aquellas hechas con toda la buena voluntad. Lo que queremos indicar es que la broma a la que nos referimos no está impulsada por la buena voluntad, sino que más bien es por la incomodidad del bromista. Por eso quien tiene razón es otro personaje de la novela cuando afirma que: "ningún movimiento que se plantee transformar el mundo soporta la burla ni el desprecio, porque eso es un óxido que todo lo disuelve" (Kundera, 1967, p. 254).

Lo atinado de esta observación estriba en que explícita los motivos últimos de la broma que estamos exponiendo, a saber, el desprecio y la burla; y de estos motivos comenta que son óxido que todo lo disuelve. De todos modos, el propósito de esta primera parte es exponer en qué consistió la broma en la novela que estamos a punto de analizar. Y, como vamos a tener la oportunidad de ir viendo, cuando una broma acontece, están involucrados muchos más sujetos que el mero bromista. Y en primer lugar está la persona que inmediatamente padece la broma.

\section{Quien padece la broma}

En toda broma siempre hay alguien tan profundamente ingenuo que se la cree enteramente. Hay que buscar, por lo tanto, los mecanismos últimos que explican en qué se funda dicha creencia. Ludvik, el personaje principal de nuestra novela, atribuye a los hados la capacidad que tienen estos personajes de creer. Evidentemente, cree que también este es el caso. Pero está claro que también esta interpretación es una especie de burla de nuestro bromista, porque no es, rigurosamente hablando, un don que provenga de los hados.

Si este don no proviene de los dioses entonces ¿cuál es el mecanismo último que nos puede permitir entender el comportamiento de aquel que se cree la broma? Aquí hay que recordar que la broma fue escrita en una tarjeta postal, por lo tanto, se corría el riesgo de que dicha postal hubiera sido vista por alguien más y, ante este peligro, la salida más inmediata es la de querer protegerse de cualquier mal interpretación que se pueda hacer de este documento. Por lo tanto, hay en la persona que se cree la broma una especie de vulnerabilidad, de la que con toda prisa busca liberarse; por eso el que padece la broma pretende no ser involucrado en dicha broma. Son tantas las preguntas, las inquietudes

1 Si tuviera que hacer un análisis político de esta novela, este texto tendría que comentarlo de otro modo, dado que se trata de un texto central en la posición política de Milan Kundera. 
que probablemente se le venga a su cabeza, que, en el caso de Marketa, es probable que también pensara en lo que hubiera podido ocurrir si los camaradas descubrieran la postal enviada por el camarada Ludvik. ¿La involucrarían? ¿Pensarían que tiene las mismas opiniones del camarada Ludvik? Es decir, el que padece la broma busca, principalmente, ponerse a salvo, proteger su espalda, evitar cualquier sospecha que pueda involucrarlo.

Una vez establecido lo anterior, también hay que decir que existen personas que fácilmente lo creen todo; y aquí sí tiene razón Ludvik cuando escribe que "Marketa era una de esas mujeres que se toman todo en serio [...] y a las que los hados les han otorgado la capacidad de creer, como característica principal" (Kundera, 1967, p. 36).

Es interesante observar que esta facilidad de creer nuestro personaje se la atribuye a una determinada capacidad. Es que los que creen todo pueden creer, así como pueden hablar, así como pueden caminar, así como pueden aprender. Estos personajes, también pueden creer, y es, justamente, en esta capacidad de creer en la que reside, según Ludvik, la peligrosidad de estos personajes.

Es curioso que la capacidad de creer se ponga en función únicamente de lo que podemos llamar las propiedades efectivas de las cosas. Las cosas son; como son y si son como son no resisten ninguna otra interpretación que lo que están manifestando. En el caso que Marketa, sea tal y como la describe Ludvik, aquella capacidad de creer no le permite discernir que las cosas puedan parecer lo que no son. Marketa fácilmente establecería que las cosas parecen lo que son $\mathrm{y}$ viceversa; las cosas que son se manifiestan en su parecer.

Además, esa increíble capacidad de creer tampoco le permite a Marketa ver que las cosas no simplemente son como son, sino que, en las propiedades efectivas que las cosas poseen, se reflejan unos rasgos perfectos que, en rigor, manifiestan la plenitud de dicha cosa. Pero para todo esto, parece que Marketa está imposibilitada de poder ver. Por ello Ludvik escribe que "no era capaz de ver más allá de las cosas y no veía más que las cosas en sí mismas" (Kundera, 1967, p. 40).

Quiere con ello indicar la imposibilidad de comprensión que tienen estos personajes que fácilmente creen lo que se les dice; esto queda claramente establecido cuando el mismo Ludvik comenta que Marketa: «se dejaba arrastrar por todos los entusiasmos de la época, pero en el momento en que era testigo de alguna actuación política basada en el principio de que el fin justifica los medios perdía su capacidad de comprensión» (Kundera, 1967, p. 40). 


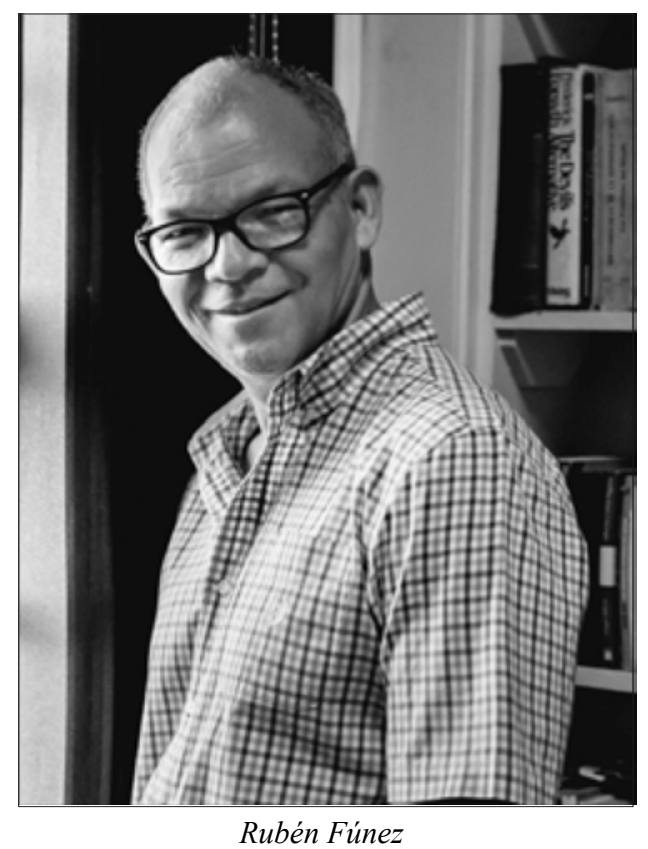

Estaba muy capacitada para describir los medios, pero imposibilitada para ver la actuación de los fines; no podía ver cómo los fines estaban implicados en los medios, su creencia se limitaba a la descripción de los medios tal y como se manifestaban, en esto reside la profunda ingenuidad de los que están capacitados únicamente a creer. Pero además de estos personajes en toda broma existe un tercer implicado, que, generalmente, es una persona muy "audaz", que cree interpretar adecuadamente la broma.

\section{Hermeneuta de la broma}

Toda broma involucra a un bromista y a quien padece la broma; pero en algunos casos ocurre que quien padece la broma considera que las consecuencias de dicha broma involucra las consecuencias a muchas más personas, por eso recurren a árbitros para que juzguen la broma; estos árbitros están empoderados, y de este empoderamiento les viene la creencia de ser portadores de todas aquellas verdades que van a permitir que los seres humanos sean mejores y que las sociedades sean mejores; estos árbitros han descubierto los secretos de cómo construir un mundo mejor, y, por lo tanto, todos aquellos que los trivializan son considerados como sujetos peligrosos. Desde esta perspectiva, los árbitros poseen al menos tres características que aplican a la interpretación que hacen de las bromas. En primer lugar, hacen uso de una lógica férrea con la que poco a poco van desvelándole al bromista no solo su culpabilidad, sino los motivos 
últimos en los que descansa la broma. En segundo lugar, su lógica se nutre de la situación en la que se encuentran inmersos, y, finalmente, se trata de personas que íntimamente se consideran los defensores no solo de la verdad, sino de la institución que protege dicha verdad.

Este tercer rasgo es evidente en la novela cuando Kundera le hace decir a Pavel, al comentar las razones por las cuales se ha casado con Helena: "No nos hemos casado por amor sino por disciplina de partido" (Kundera, 1967, p. 23), queriendo indicar con ello que las decisiones no son tomadas por los individuos aislados, sino que responden al interés de la organización. El individuo, en tanto individuo, ha dejado de existir y en su lugar aparece la institución y justamente por esto Pavel puede afirmar que "el hombre nuevo se diferencia del viejo porque supera en su vida la contradicción entre lo público y lo privado" (Kundera, 1967, p. 24). Rigurosamente hablando no existe tal contradicción sino la presencia masiva de lo público.

Pero, en segundo lugar, el árbitro se nutre de la tradición en la que está inmerso, del conjunto de valores que se consideran no solo válidos, sino un crimen de lesa humanidad no reconocerlos como tales. Al respecto, Kundera escribe, recordando el reportaje al pie de la horca de Fucik: "Tardaste mucho, muerte, en venir. Y sin embargo yo tenía la esperanza de que no nos conociéramos hasta dentro de muchos años. De que iba a vivir aún la vida de un hombre libre, de que aún iba a trabajar mucho y amar mucho, y a cantar mucho y a vagar por el mundo..." (Kundera, 1967, p. 210).

Se trata de un hombre que ama la vida, que ama el trabajo, que ama la libertad. $\mathrm{Y}$ es precisamente forzado por este amor que es capaz de sacrificarse, por eso apunta nuestro novelista: "yo amaba a la vida y por su belleza fui a batirme. Os amaba a vosotros, hombres, y era feliz cuando correspondíais a mi amor y sufría cuando no me comprendíais..." (Kundera, 1967, p. 210).

Se trata de héroes coherentes, de héroes que han depositado toda su fe en su lucha, que no están dispuestos a que nada ni nadie distraiga lo demás del enorme sentido que tiene su compromiso, por eso se entiende enseguida que con toda valentía afirme: "Que la tristeza no esté nunca unida a mi nombre. Este es mi testamento para vosotros, papá, mamá y hermanas mías, para ti, Gustina mía, para vosotros camaradas, para todos aquellos a quienes he querido..." (Kundera, 1967, p. 210).

De esta tradición y de aquella militancia se nutre la lógica férrea con la que se interpreta la broma. Apuntemos resumidamente el proceso lógico de esta interpretación. Las inquietudes que fueron hilvanándose. En el juicio que se le hizo a Ludvik, pueden apuntarse del modo como sigue: ¿¿Conoces a Marketa?, ¿le 
has escrito?, ¿recordás lo que escribiste?, ¿qué te escribió Marketa?, ¿te escribió que el cursillo había un espíritu sano?, ¿te escribió que se había dado cuenta de la fuerza que tenía el optimismo?, ¿qué opinas del optimismo?, ¿te consideras optimista?, ¿tú crees que se puede edificar el socialismo sin optimismo?, entonces, ¿tú no eres partidario de que en nuestro país se edifique el socialismo? Da lo mismo como lo hayas escrito. Lo escribas rápido o despacio, de pie o en la mesa, no puedes escribir más que lo que está dentro de ti” (Kundera, 1967, pp. 43-45).

Se trata de preguntas cuyas respuestas inexorablemente llevarían al acusado a que se declarara culpable. Por esta razón Kundera observa que cuando al acusado le tocó el turno de hablar en lugar de defenderse condenó lo inadecuado y basto de su broma; y habló de su individualismo, de su intelectualismo, de su distanciamiento del pueblo, detectó incluso autocomplacencia, escepticismo y cinismo en su propia vida (Kundera, 1967, p. 212).

Toda broma arrastra consecuencias que pueden determinar la vida de un ser humano.

\section{Consecuencias de la broma}

Es sorprendente e incluso escandalosa la manera cómo una broma puede determinar la totalidad de la vida de una persona. Lo malicioso de una broma es que frecuentemente el bromista no es consciente de las consecuencias que están incoadas en la broma misma. Es casi enojoso decir que una supuesta broma es capaz de deteriorar todas las relaciones que en la vida ha ido construyendo un individuo. Esto queda meridianamente claro en la manera como nuestro personaje describe este radical deterioro que fue desencadenado por la broma que describimos: "Sí. Todos los hilos habían sido arrancados. Había quedado cortado el estudio, la participación en el movimiento, el trabajo, la red con los amigos, había quedado cortado el amor y hasta la búsqueda del amor, había quedado cortado, sencillamente, todo el sentido de mi trayectoria vital" (Kundera, 1967, p. 61).

Kundera quiere que nos hagamos conscientes de que las consecuencias de la broma no solo afectan a lo que podríamos denominar la materialidad de nuestra vida, sino a todos aquellos hilos espirituales que son tan fundamentales como soporte de la propia vida. A eso apunta cuando dice que no solo sus amigos se fueron, que no solo la universidad se fue, sino que incluso el amor, sino que incluso la búsqueda del amor y, más radicalmente, todo aquello que le daba sentido a su vida. En este caso, las consecuencias de la broma son globales, abarcan la totalidad de la vida de un individuo.

Parece que, una vez rotos todos estos hilos, una vez que desaparecen todas estas vinculaciones, perdemos el control sobre nuestra propia vida. Es que una 
Pieza de Exposición

Museo Universitario de Antropología
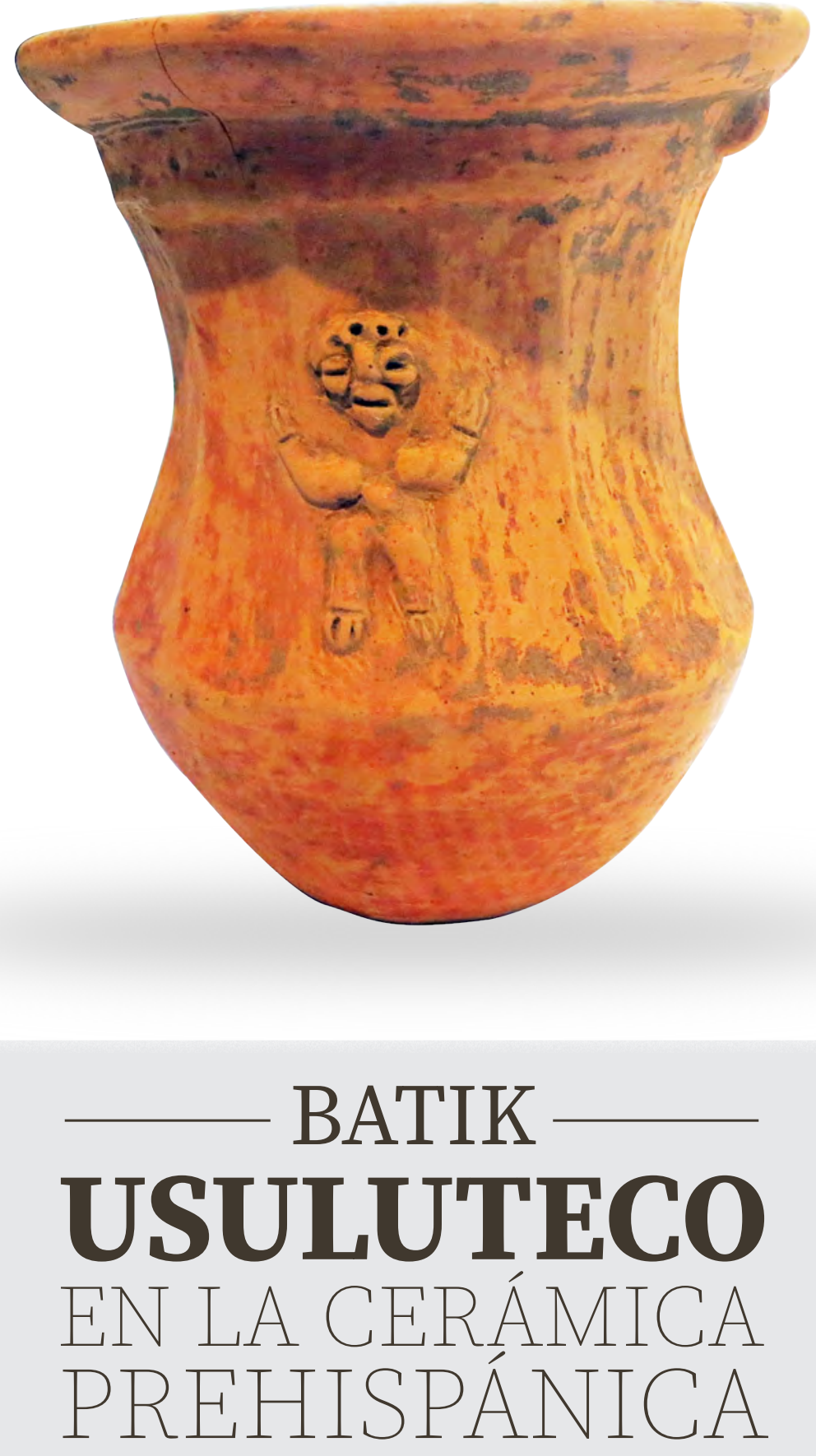
vida sin un significado, es que una vida sin un sentido, pierde toda posible orientación, pierde toda posible meta, pierde toda posible finalidad. Por lo tanto, pareciera que el bromista cede su control a las diversas situaciones por las que atraviesa no como sujeto, sino más bien como cosa. Esta falta de control está magistralmente descrita cuando Ludvik reflexiona del modo como sigue:

Me había dado lástima. Lástima por la conciencia clara de que esta situación no era algo excepcional que hubiera elegido por exceso, por capricho, por el inquieto deseo de conocerlo y probarlo todo, (lo sublime y lo soez), sino que se había convertido en la situación habitual de mi vida actual. Que era ella la que marcaba con precisión el círculo de mis posibilidades, que era ella la que dibujaba con precisión el horizonte de la vida afectiva que desde ahora me pertenecía. Que esta situación no era manifestación de mi libertad, (como podía haberla interpretado si me hubiera ocurrido un año antes), sino una manifestación de mi determinación, de mi limitación, de mi condena. Y sentí miedo. Miedo de este lamentable horizonte, miedo de este sino. Sentí que mi alma se encerraba en sí misma, que empezaba a retroceder ante todo esto y al mismo tiempo me espantaba que no tuviera donde retroceder para escapar del cerco (Kundera, 1967, p. 72).

Se trata de una situación que va progresivamente arrinconando a las personas que están inmersas en ella sin dejarles ninguna escapatoria, es una situación abrumadora. Hay que también decir que, justamente por haber cedido el control a las diversas situaciones que se están sufriendo, se van creando las condiciones para que todos los demás lo traten no como un sujeto, sino como una cosa que no solo carece de derechos, sino que incluso de todo deber y de toda obligación, que es una cosa que lo único que sabe hacer es ejecutar órdenes; es una realidad en la que no cuenta ni lo que piensa ni lo que siente. En otras palabras, que ha perdido toda su dignidad. Por eso Kundera observa que "La cosificacion a la que nos vimos sometidos me pareció durante los primeros días completamente opaca, impenetrable; las funciones impersonales que desempeñábamos, siempre cumpliendo órdenes, reemplazaron nuestras manifestaciones humanas". (Kundera, 1967, p. 58).

Es la conciencia más descarnada de que, incluso no termina de saber quién lo está controlando, de que, en lugar de ser sujetos en la historia, lo que en la realidad se sucede es que se sufre la historia. Es la descripción más clara de la perplejidad, de la incertidumbre, de no saber qué hacer, porque se tiene la impresión de que no es más que un títere bajo el control de un titiritero, del que tampoco se tiene plena conciencia de quién es. El bromista no es el que pilotea su vida, sino que lo hacen circunstancias que no solo están fuera de su control, sino que desconoce quién tiene el control. Esta experiencia es descrita así: "Me 
pareció que había una fuerza sobrenatural que me cerraba el camino y que me quitaba siempre de las manos aquello a lo que yo deseaba dedicar mi vida, lo que anhelaba, lo que me pertenecía, [...] que siempre me lo quitaba todo y siempre así porque sí, sin motivo alguno" (Kundera, 1967, p. 127)

En este texto, Kundera nos ofrece una clave interpretativa no solo de la falta de control en la que está el bromista, sino una explicación de cómo las consecuencias de una broma pueden sacar lo peor que está anidado en el fondo del corazón humano. El texto anterior afirmaba que el bromista no termina de asumir la situación en la que se encuentra, porque piensa que no ha sido comprendido adecuadamente y que todo se debe a un mal entendido. Sin embargo, este hecho de no asumir la responsabilidad respecto a lo que le compete al bromista es lo que no le permite no solo asumir la situación en la que se encuentra, sino desvelarle los mecanismos más perversos con los que está equipado todo ser humano. Pero ¿cuál es la experiencia que saca lo peor que se lleva dentro? Un amigo de Ludvik observa que

Se sigue acordando de aquella reunión plenaria en la que todos por unanimidad levantaron la mano contra usted y estuvieron de acuerdo en que se destruyera su vida. Usted no se lo ha perdonado. No sólo a ellos como personas individuales. Eran cerca de cien y esa ya es una cantidad que se puede convertir en un pequeño modelo de la humanidad. Usted no se lo ha perdonado nunca a la humanidad. Usted desde aquel momento no confía en ella y siente hacia ella rencor. Yo le comprendo, pero eso no impide que tal tipo de rencor hacia la gente sea horrible y pecaminoso. Se ha convertido en su maldición. Porque vivir en un mundo en donde no se le perdona nada nadie, donde nadie puede redimirse, es lo mismo que vivir en el infierno. Usted vive en el infierno (Kundera, 1967, p. 248).

El infierno no son los otros - como inocentemente dijo Sartre-, sino que el infierno es ese terrible resentimiento que experimenta nuestro personaje al sentirse tan injustamente tratado; y lo que quiere acentuar nuestro novelista es que este resentimiento es algo que afecta, que contamina la totalidad de la vida de Ludvik. Todo esto es confirmado en la medida en que se observa que "se quedó amargado hasta el fondo del alma, convencido de que le habían hecho una gran injusticia. Ese sentimiento de injusticia sigue hasta hoy determinando toda su postura ante la vida (Kundera, 1967, p. 254).

Una persona destruida de esta manera, es incapaz de descubrir la más mínima ternura. Por eso, en lo que sigue de esta sección, vamos a describir dos situaciones aparentemente excluyentes, pero que en el fondo están unidas por el enojo, por 
el deterioro, por la rabia que siente el bromista contra todo y contra todos. Los dos casos que vamos a describir son, primero, el que tiene que ver con Lucie, y segundo, el que tiene que ver con Helena.

Nuestro autor describe detalladamente la manera cómo conoció a Lucie. Cuenta que

Fue precisamente la particular lentitud de Lucie lo que me atrajo tanto, una lentitud de la que parecía irradiar la resignada convicción de que no hay a dónde ir tan de prisa y de que es inútil extender las impacientes manos hacia algo. Sí, quizás fue precisamente esa lentitud llena de tristeza la que me impulsó a observar desde lejos a la muchacha, a fijarme cómo se acerca la taquilla, cómo saca las monedas, cómo coge la entrada, cómo mira hacia la sala y cómo se da otra vez la vuelta y sale al patio (Kundera, 1967, p. 76).

Es curioso observar que todos los rasgos que cree encontrar en esta muchacha están íntimamente vinculados con sus propios rasgos. Al escucharlo, se tiene la impresión de que también Lucie es una muchacha acorralada, una muchacha que no tiene adónde ir, una muchacha que ha sido duramente golpeada por la vida. En este sentido, cree haber encontrado su alma gemela. Un alma gemela que, además de reflejar su propia vida, podía nutrirlo con toda una serie de valores de los que estaba necesitado. Por ello Ludvik comenta que se fijó "en su cara, discretamente hermosa, hermosamente discreta; sentí que en aquella muchacha había serenidad, sencillez y humildad y que esos eran los valores que yo necesitaba" (Kundera, 1967, p. 77).

Esta alma gemela es lo único con lo que Ludvik cuenta, por eso no es exagerado que sienta que Lucie lo es todo para él; es que efectivamente con lo único que contaba era precisamente con aquella muchacha. En la vida desesperada que le tocaba vivir, Lucie vino a colmarlo, vino a llenarlo y vino a ofrecerle su ternura; ternura de la que, en toda la vida de nuestro personaje, estuvo desprovisto. En rigor, con lo que no contó en ninguna de sus relaciones anteriores fue justamente con ternura; sus relaciones con los compañeros, sus relaciones con el partido, su relación con la universidad, su relación con el pueblo no necesariamente estaba permeada de ternura, sino que más bien tenemos la impresión de que era por la indiferencia, que era por el cinismo, que era por el doblez. Lucie le abre un mundo en el que con facilidad descubrió justamente aquello de lo que siempre había carecido, por eso afirma que "hasta entonces Lucie había sido para mi todo lo posible: una niña, una fuente de ternura, una fuente de consuelo, y hasta un modo de escaparme de mí mismo, lo era para mí, casi al pie de la letra, todo" (Kundera, 1967, p. 92). 
Y como consecuencia de su broma, no obstante, terminó perdiendo a Lucie, una pérdida que - como el lector se ira enterando- fue producto de su incapacidad de ver que la ternura era solo ternura. Un ser humano golpeado del modo como fue golpeado nuestro personaje está imposibilitado no solo para mantener relaciones duraderas, sino para descubrir la gratuidad que hay en la base de estas relaciones. La pérdida de Lucie puede perfectamente entenderse como consecuencia del proceso que desencadenó su broma, y, al perderla, dolorosamente cuenta que escribió "una carta, larga y lastimera, y le pedí a Lucie que volviera, que tenía que verla, que ya no quería nada de ella, sólo que estuviera, que pudiera yo verla y saber que estaba conmigo, que estaba, que era..." (Kundera, 1967, p. 131).

Pero es absolutamente consciente de que la pérdida de Lucie es definitiva, por eso comenta que ella "permanece dentro de mí constantemente con una callada nostalgia; la anhelaba como se anhela algo que se ha perdido definitivamente" (Kundera, 1967, p. 180).

El siguiente caso que queremos describir, y que explicita en toda su monstruosidad aquello en que se convirtió nuestro personaje, es la relación que mantiene con Helena. Helena es la mujer de uno de los compañeros que levantaron su mano para expulsarlo, tanto de la universidad como del partido. Helena se enamora de él; y la posee para vengarse de quién considera su enemigo. Este episodio confirma, minuciosamente, aquello de que una persona hiere solo y justamente ahí donde se ha sido herido. Una de las situaciones que más deploraba Ludvik fue la cosificación a la que fue sometido. Sin embargo, el modo como trata a Helena es precisamente considerándola como una cosa. Describe la situación con una frialdad casi maquiavélica. En este sentido, recuerda que

Registré cuidadosamente cada uno de los detalles de la escena: [...] se trataba de apoderarse de un mundo íntimo, ajeno, totalmente preciso, y tenía que abarcar ese mundo ajeno en una sola tarde, en un solo acto sexual en el que no tenía que ser solamente aquel que se entrega a hacer el amor, sino también aquel que depreda y vigila al huidizo botín y debe estar por lo tanto absolutamente alerta (Kundera, 1967, p. 215)

Y más abajo sigue apuntando que puso

la palma de la mano sobre esa cara; la puse como se pone sobre un objeto al que podemos dar vueltas, golpear, destrozar o machacar; le di vuelta a su cabeza hacia un lado; luego al otro lado; volví varias veces su cabeza de ese modo hasta que de repente ese voltear se convirtió en la primera bofetada; y en la segunda; y en la tercera; [...] su mentón se levantaba hacia mí y yo le pegaba y le pegaba y le pegaba; y luego vi que no sólo 
su mentón sino también sus pechos se elevaban hacia mí y la golpeé en los brazos, en las caderas, en los pechos... (Kundera, 1967, p. 217)

Y concluye esta descripción como el guerrero que corta la cabeza de su contrincante y la muestra victoriosamente como trofeo:

Me levanté y atravesé la habitación tambaleándome; abrí la puerta y entré al cuarto de baño; abrí el grifo y me lavé con agua fría la cara, las manos y el cuerpo. Levanté la cabeza y me miré al espejo: mi cara se sonreía, cuando la descubrí en esa actitud — sonriéndose - la sonrisa me dio risa y me eché a reír (Kundera, 1967, p. 217)

Asistimos a la más profunda bajeza en la que se puede caer producto de las consecuencias de una broma irreflexiva.

Dice Herman Hesse que en todo ser humano habita un hombre y una bestia, y que el hombre es hombre y que la bestia es bestia, queriendo indicar con ello que cuando la bestia actúa como bestia no tiene ninguna reserva. Todo ello puede llevarnos a pensar en que los seres humanos estamos condenados a tener que dejar actuar la bestia que llevamos dentro, $y$, en este sentido, que no hay manera de poder escapar. Sin embargo, Milan Kundera considera que los seres humanos somos perfectibles y que siempre tenemos la oportunidad de cambiar, por eso lo que hay que preguntarle a nuestro novelista es precisamente a dónde recurrir y de qué elementos apropiarse para poder redimirnos de la monstruosidad que han ido fraguando las diversas vicisitudes por las que atraviesa los seres humanos.

\section{Redención del bromista}

Kostka - en un texto citado más arriba - describe con precisión la situación en la que se encuentra Ludvik. Para aquel personaje, este se encuentra en el mismo infierno. La degradación ha sido tan grande que ha tocado fondo. Es verdad que cuando se toca fondo se encuentra algo firme desde el cual impulsarse. Es verdad que cuando se toca fondo ya no se puede seguir bajando en la degradación y, por lo tanto, la única oportunidad que se presenta es impulsarse, con las fuerzas que todavía quedan, hacia arriba. En este caso impulsarse hacia arriba es una mera metáfora, para describir la necesidad de salir de la degradación en la que se encuentra. Hay en este esfuerzo por salir, al menos, dos caminos. El primero consiste en replegarse en uno mismo para descubrir en la interioridad no solo los recursos para salir desde donde nos encontramos, sino incluso los nudos mentales que nos atan en ese fondo. El segundo consiste en buscar en aquellas raíces, que son más bien históricas, que son más bien populares, que son más bien sociales, los recursos con los que se pueden ir restañando poco a poco las heridas que ha ido dejando una vida denigrante. 
Respecto a la primera salida, hay que decir que no es a la que recurre nuestro personaje. Y la razón parece muy clara: rigurosamente hablando, Ludvik nunca pensó más que en él mismo, nunca estableció auténticas relaciones, nunca estuvo realmente preocupado por los demás; parece que estaba apoltronado en su propia realidad, pero esta realidad se le ha convertido en una terrible incomodidad. No se encuentra bien consigo mismo, no es un huésped bienvenido en su propia interioridad. No es bien acogido por él mismo. Por todas estas razones, parece que su curación tiene que provenir de su regreso, de su vuelta a aquellas fuentes nutricias que están más allá de su propia individualidad; y aquí va a encontrar una especie de acogida, una especie de perdón, que vamos a esperar que pueda convertirse en el medio para perdonarse a sí mismo. Y justamente de esta acogida es de la que se quiere hablar en la última parte de este ensayo.

Es una verdad básica no solo de la psicología, ni solo de la filosofía, ni solo de la sociología que los seres humanos no podemos comprendernos si estamos replegados sobre nosotros mismos. Comte pensaba que el individuo es una abstracción y que lo concreto es la sociedad. Entonces la solución a las grandes dificultades por las que pasamos los seres humanos quizás tengan su respuesta no mirándose al interior de cada cual, sino poniendo nuestra atención en lo que está ocurriendo en la sociedad. Refiriéndonos al personaje de nuestra novela, es fácil constatar que mucho tiempo de su vida la pasó girando en torno a sí, pero, en la medida en la que esto ocurría, en lugar de clarificarse más bien da la impresión de que se hundía más y más en sí mismo. La pregunta que forzosamente tenemos que hacer, en el caso que nos ocupa, es ¿qué fue lo que encontró nuestro personaje en la sociedad que le permitió, quizás exagerando un poco, redimirse? Y parece que fue justamente llegar, por medio de su cultura, de sus valores, de sus tradiciones, a las raíces de su propia existencia. Milan Kundera, con un increíble conocimiento de la cultura de su pueblo, va vinculando las canciones populares con la historia de su nación; y parece que es esta historia la que le sirve de vehículo para poder encontrarse con sus propias raíces. Además, Kundera expone este proceso de una manera clara y magistral. La historia de la música va desvelando la historia de su pueblo, por esta razón recurre a la metáfora de la bailarina con velo, para indicar con ello cómo la música es un sistemático ir quitando el velo que cubre la historia de su pueblo. Aún a riesgo de citar por extenso, me parece que es inexorable en la medida en la que solo de la mano de nuestro autor vamos a ir desentrañando la íntima vinculación que hay entre la música, la cultura, los valores y la historia.

Cuando te encuentras cara a cara con nuestra música popular, es como si ante ti bailara una mujer de las mil y una noches y se fuese quitando un velo tras otro. 


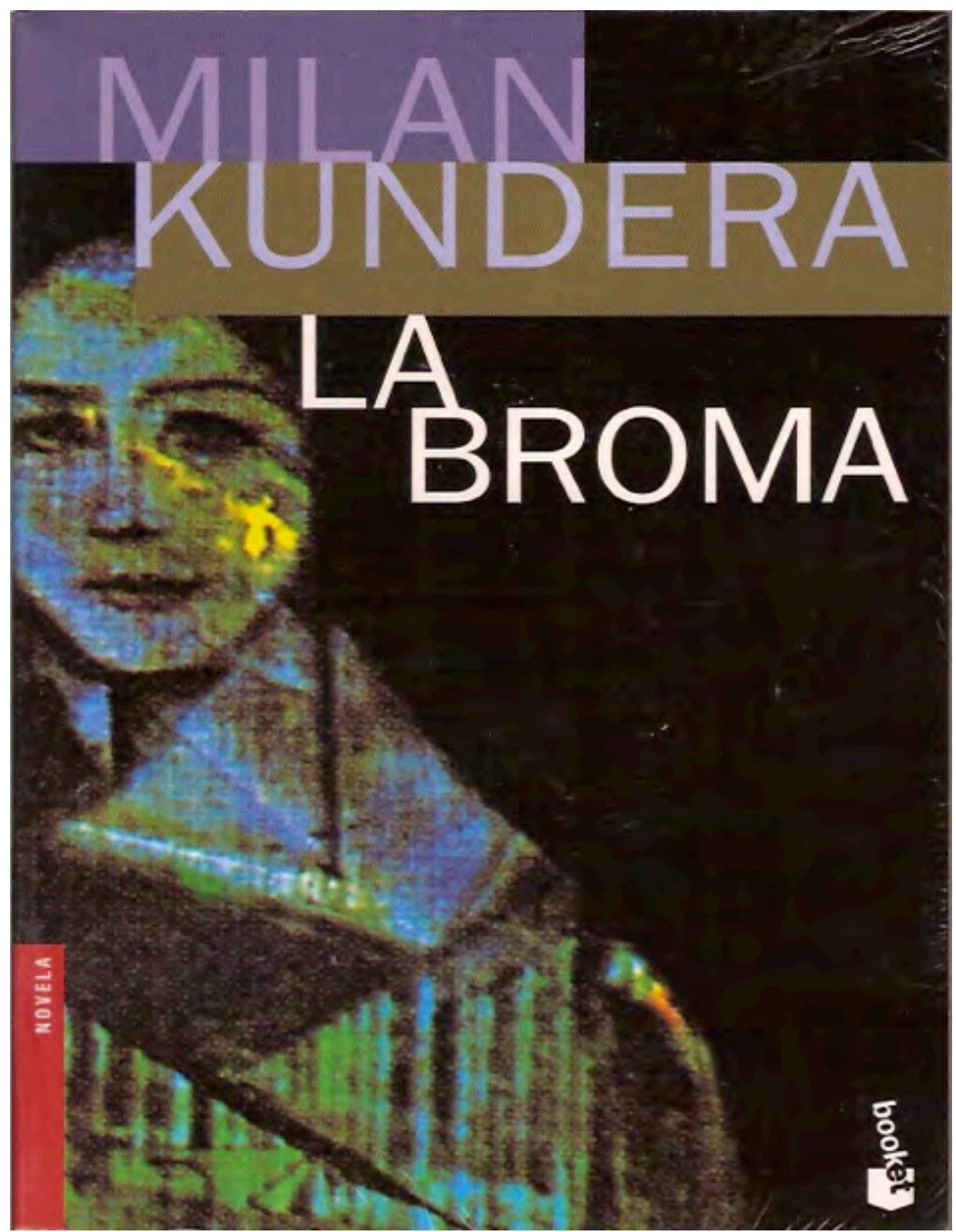

Mira. El primer velo. Es de tela basta, estampada con dibujos triviales. Son las canciones más jóvenes que provienen de los últimos cincuenta, setenta años. Vinieron de occidente, de Bohemia. Las trajeron las orquestas de instrumento de viento. Los maestros las enseñaron a cantar en el colegio a nuestros hijos. Son en su mayoría canciones en modo mayor, de tipo europeo occidental corriente, sólo un poco adaptadas a nuestro ritmo. 
Y el segundo velo. Ese ya es mucho más variado. Son canciones de origen húngaro. Acompañaron a la invasión del idioma húngaro a las regiones eslavas de la corona de Hungría. Los conjuntos gitanos la difundieron durante el siglo diecinueve por todo el Reino Unido. Quién no las conoce. Las czardas y otras canciones, todas ellas con el característico ritmo sincopado en la cadencia. Cuando la bailarina se quita este velo aparece otro. Mira, son las canciones de la población eslava local, del siglo dieciocho y el diecisiete.

Pero aún más bello es el cuarto velo. Son canciones aún más antiguas. $\mathrm{Su}$ edad se remonta hasta el siglo catorce. En aquella época fueron llegando hasta nosotros por las cumbres de los Cárpatos desde el este y el sudeste de Valaquia. Pastores. Sus canciones pastoriles y de bandoleros no saben nada de acordes y armonías. Han sido pensadas sólo melódicamente, en sistema de tonos arcaicos. Las flautas le dieron a su melodía un carácter específico.

Y cuando cae este velo ya no hay debajo de él ningún otro. La bailarina está completamente desnuda. Son las canciones más antiguas. Su origen está en las viejas épocas paganas. Se basan en el más antiguo sistema de pensamiento musical. En un sistema de cuatro tonos, el sistema tetracórdico. Canciones de siega. Las canciones más íntimamente unidas a las ceremonias de la aldea patriarcal. La canción popular o la ceremonia popular, son un túnel a través de la historia como en el que se ha conservado mucho de lo que arriba destruyeron hace ya tanto tiempo las guerras, las revoluciones y la civilización despiadada. Es un túnel por el que puedo ver hasta muy atrás. Veo al viejo mundo eslavo (Kundera, 1967, pp. 148-149).

Queremos indicar que la única intención de haber recurrido a este extenso texto es porque creemos que nos indica de manera genial, la manera como Ludvik pudo ser capacitado para redescubrir las raíces a las que pertenecía por eso no es extraño que nuestro personaje afirme que

...yo me sentía feliz dentro de estas canciones, [...] en las que la tristeza no es un juego, la risa no es falsa, el amor no es ridículo y el odio no es tímido, donde la gente ama con el cuerpo y el alma, [...] donde cuando están alegres bailan, cuando están desesperados se tiran al Danubio, donde el amor sigue siendo amor y el dolor dolor y los valores aún no están devastados, y me pareció que dentro de estas canciones estaba en casa, que había partido de ellas, que su mundo era mi estigma original, mi hogar, al que había defraudado, pero que era por eso mismo más aún 
mi hogar, $[\ldots]$ pero enseguida me di cuenta también de que este hogar no era de este mundo, [...] que lo que cantábamos y tocábamos era sólo un recuerdo como una reminiscencia, la conservación de la imagen de algo que ya no existe, y sentí como la tierra firme de este hogar se hundía bajo mis pies, cómo caía, como sostenía el clarinete junto a la boca y me hundía en la profundidad de los años, en la profundidad de los siglos, en una profundidad inconmensurable, $[. .$.$] y me dije con$ sorpresa que mi único hogar es precisamente este hundimiento, $[\ldots]$ y seguí así entregado a ella, experimentando un dulce vértigo (Kundera, 1967, p. 326).

Pero un aspecto de suma importancia es que esta nueva etapa en la que se encuentra nuestro personaje, aunque podemos afirmar que le ha permitido superar la etapa anterior, esta superación hay que entenderla adecuadamente en la medida en que, en rigor, lo que ha ocurrido es que se ha podido rescatar lo que mejor da cuenta de nuestro personaje. No se trata de diluirse y de perder la propia contextura, sino este volver a sus raíces es el gesto más revolucionario, es el gesto que tiene una radical dimensión crítica, frente al modo como se ha querido domesticar la cultura popular. De hecho, este redescubrirse puede entenderse no solo como el descubrirse de nuestro propio autor, sino como un redescubrirse de la propia cultura. En este sentido, Ludvik concluye afirmando que

podía amar al mundo de los trajes tradicionales, las canciones y las orquestas folklóricas porque [...] lo había visto en su pobreza y sobre todo en su abandono, había sido abandonado por la ceremonia y la publicidad, abandonado por la propaganda política, por las utopías sociales, abandonado por el batallón de funcionarios culturales, abandonado por el afectado entusiasmo de mis coetáneos, aquel abandono lo purificaba, era un abandono recriminatorio, que lo purificaba [...]; aquel abandono lo hacía relucir como una especie de irresistible belleza final; aquel abandono me lo devolvía (Kundera, 1967, p. 321).

En definitiva, lo que ha ocurrido podemos describirlo como un encuentro que ha posibilitado un doble descubrimiento. Por un lado, el descubrimiento de Ludvik determinado por la cultura de su pueblo, y por otro, el redescubrimiento de la cultura determinado por el encuentro con Ludvik. Pero es redescubrirse en un proceso de hundimiento. Un mundo se está olvidando; y en este olvido es en el que se encuentra nuestro personaje. El descubrimiento que hace Ludvik es que lo ocurrido a él mismo es algo que le está ocurriendo también a su pueblo. Ambos han corrido la misma suerte. 


\section{Conclusión}

Quiero indicar que no he pretendido en este ensayo, ni siquiera superficialmente, exponer el propósito que Milan Kundera tuviera al escribir su novela. Es claro que tiene su propósito de crítica política, determinado por los sucesos ocurridos en 1948 con el ascenso al poder del Partido Comunista. Ascenso que determinó no solo la vida económica y política del pueblo checoslovaco, sino la vida cultural y universitaria. Milan Kundera es un crítico férreo del fanatismo que abunda en los salones universitarios. Se trata de un ambiente permeado, todo él, por una adhesión sin crítica a los partidos comunistas. Vuelvo a insistir en que mi ensayo, aun siendo consciente de esta dimensión crítica de la novela, no ha sido la que ha predominado en la lectura que he hecho de ella. Tampoco he pretendido hacer una lectura exhaustiva, que abarque todos los temas desarrollados por nuestro autor.

Creo que hay temas muy importantes que son susceptibles de ser estudiados y analizados en otros ensayos. Es posible que otros estudios puedan abordar la dimensión psicológica de cada uno de los personajes descritos con tanto rigor por nuestro autor. Esta empresa se facilita justamente porque los capítulos de nuestra novela están titulados con los nombres de cada uno de estos personajes, en los que, de acuerdo con algunos críticos, predomina el análisis psicológico.

Por ejemplo, un personaje al que valdría la pena seguirle la pista es Lucie. Frente a personas como Lucie, la pregunta que uno forzosamente tiene que hacerse es cómo nos explicamos que le vaya tan mal en la vida. Lucie, según nuestro novelista, es una muchacha inocente. Siendo muy joven fue violada por sus amigos, después conoció a Ludvik que, a pesar de que llegó a representarlo todo para su vida, va a entender que su comportamiento es parecido al de todos los demás seres humanos. En tercer lugar, conoce Kostkas. Este es un oasis encontrado en su vida. Sin embargo, es un hombre casado y tiene un hijo. Y, finalmente, la novela nos cuenta que el hombre con el que se casó es un déspota que la golpea cada vez que puede. Por lo tanto, es imposible no preguntarse qué es lo que articula a cada uno de estos sucesos. Y así como este tema hay muchos otros susceptibles de ser estudiados. Por todo esto, estamos ante una novela que debe ser leída y estudiada minuciosamente.

\section{Referencia bibliografíca}

Kundera, M. (1967). Labroma. Buenos Aires, Argentina: Emecé Editores

Reflexión del autor 


\section{Pieza de Exposición}

Museo Universitario de Antropología

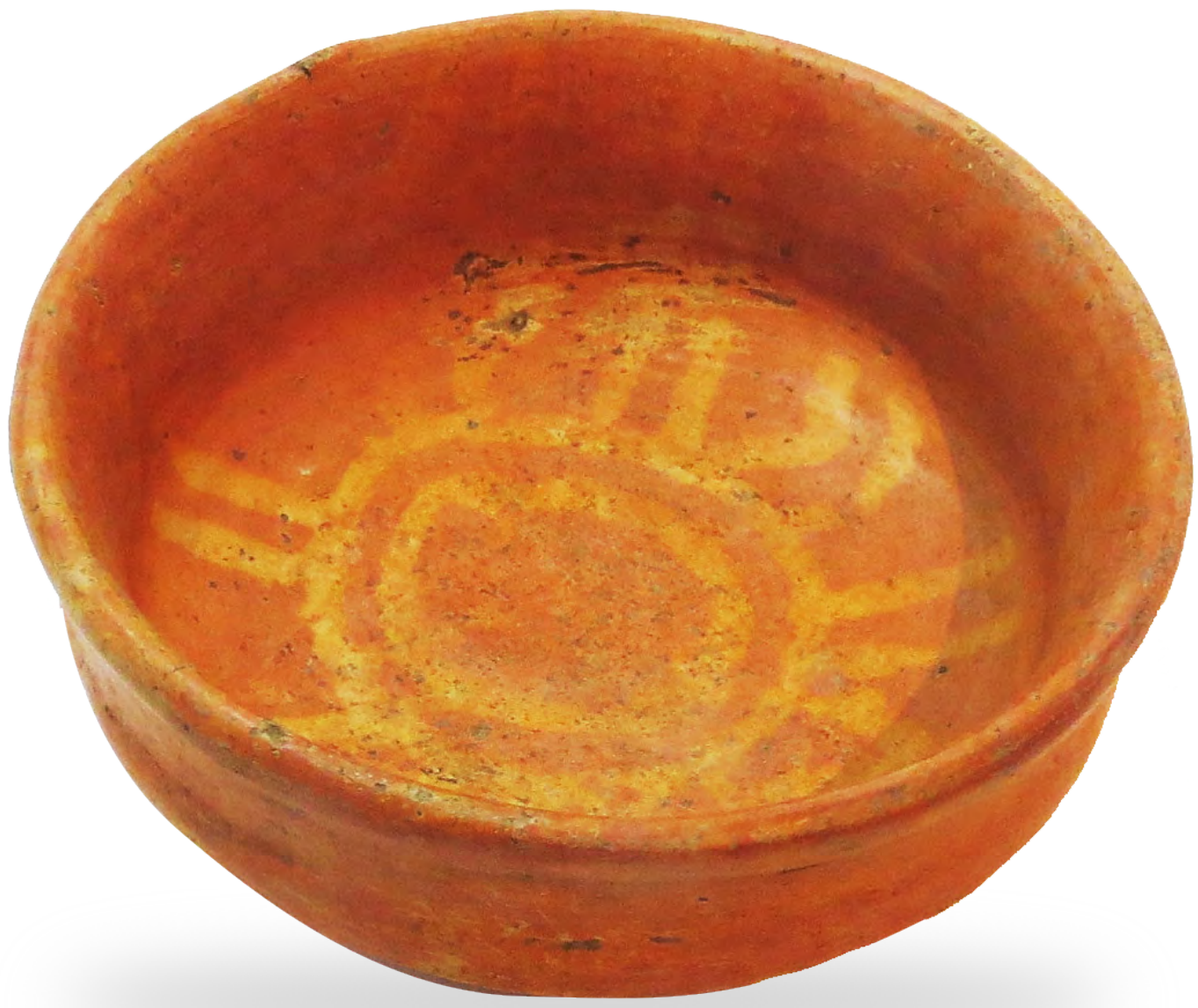

Cuenco

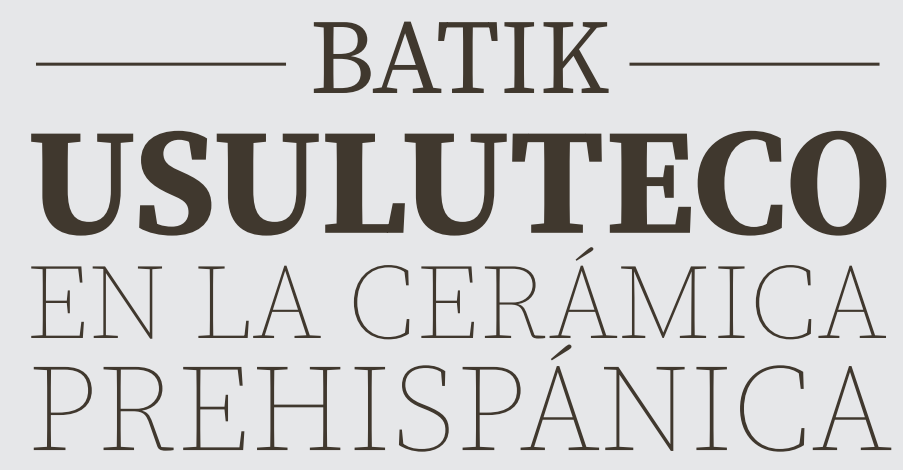

